\title{
Escribir Periodismo Feminista
}

\author{
Write Feminist Journalism
}

\author{
Elvira L. Hernández Carballido ${ }^{a}$, Mauricio E. Ortiz Roche ${ }^{b}$, María de la Luz Nalleli Martínez \\ Hernández $^{c}$
}

\begin{abstract}
:
The presence of feminism in society has allowed it to invade or gain space in different scenarios, one of which is journalism. The objective of this article is to guide those interested in writing journalistic texts from a feminist perspective. This is how we will present a brief overview of the meaning of feminism, the way in which publications with that ideology and the guidelines that have been tried to share have emerged in our country, mainly in workshops of women's organizations, to bring it to life in journalistic publications. It is affirmed that feminist journalism allows women to give voice and visibility in news events on a par with men.
\end{abstract}

Keywords:

feminism, women, journalism, equity

\section{Resumen:}

La presencia del feminismo, visto desde el planteamiento de la igualdad, ha permitido que invada o gane espacios en diferentes escenarios, uno de ellos es el periodismo. El objetivo de este artículo es orientar a quienes les interese escribir textos periodísticos desde una perspectiva feminista. Es así como se dará a conocer un breve panorama sobre el significado del feminismo, la forma en que en nuestro país han surgido publicaciones con esa ideología ética política y la manera en que se comparte, principalmente en talleres de organizaciones de mujeres, como en Comunicación e información de la mujer (CIMAC) para darle vida en las publicaciones periodística. Sara Lovera (2019), periodista y pionera en este tema, afirma que el periodismo feminista permite dar voz y visibilizar a las mujeres en los sucesos noticiosos a la par con los hombres.

Palabras Clave:

feminismo, mujeres, periodismo, equidad

\footnotetext{
a Profesora investigadora del Área Académica de Comunicación. Universidad Autónoma del Estado de Hidalgo. Email: elviracarballido62@gmail.com

b Profesor investigador del Área Académica de Comunicación. Universidad Autónoma del Estado de Hidalgo. Email: mroche@uaeh.edu.mx

c Estudiante de la Maestría en Ciencias Sociales.Universidad Autónoma del Estado de Hidalgo. Email: sakumarina_7@ @hotmail.com
} 


\section{Introducción}

\section{Introducción}

A mitad del siglo $X X$ aparece una de las obras más significativas para el movimiento feminista. El segundo sexo de la francesa Simone de Beauvoir, filósofa, feminista y referencia obligada en este tema, representa uno de los estudios más importantes de todos los tiempos. El texto resulta ya un clásico. Hoy nadie puede ignorar una de las frases más rotundas del libro.

No se nace mujer, se llega a serlo. Ningún destino biológico define la figura que reviste en el seno de la sociedad la hembra humana; es el conjunto de la sociedad el que elabora ese producto intermedio entre el macho y el castrado que se califica de femenino (Beauvoir, 2016).

Ya a finales del siglo $X X$, la corriente feminista estuvo representada por dos importantes perspectivas: el feminismo de la igualdad y el feminismo de la diferencia. Por el primero puede entenderse aquel que plantea la igualdad de derechos para las mujeres y a reivindicar la equidad de ellas y los hombres en los planos jurídicos, legales, políticos, económicos y sociales. En tanto, el segundo, privilegia fortalecer aquellas características específicamente femeninas y que han sido no valoradas (o negativamente valoradas) por la cultura patriarcal.

Es así como los antecedentes que van conformando su historia, a nuestro juicio, el feminismo no es tarea fácil de etiquetar o generalizar ya que cada mujer que se considera parte del movimiento lo ha entendido $y$ definido desde su perspectiva y hasta desde sus propias vivencias. En México, diversas investigadoras y académicas han trabajado el término y lo han definido desde su propia experiencia. Entre los objetivos del feminismo, podemos mencionar, de acuerdo con Sara Sefchovich, los siguientes:

Transformar la cultura e introducir una nueva perspectiva sobre las relaciones entre los sexos.

- Conseguir la igualdad y el respeto a la diferencia, que no son opuestos como parecería, sino necesariamente complementarios.

Replantearse el cuerpo y la sexualidad, el amor, el deseo, el placer, la reproducción y la maternidad, la ciudadanía y la participación, el poder y el empoderamiento, la identidad y la alteridad, lo simbólico y lo subjetivo.

- Luchar por el derecho a la salud (particularmente la sexual y reproductiva), al trabajo bien remunerado, al respeto de los derechos humanos, contra la violencia en todas sus manifestaciones.
Modificar el orden doméstico ancestral. (Sefchovich, 2011).

El feminismo poco a poco se ha ido introduciendo en diferentes escenarios sociales, uno de ellos es el periodismo. En México, la primera publicación que se editó fue en la Escuela de Artes y Oficios para Mujeres, esta la conformaban un grupo de jóvenes de clase media, quienes en su materia de Imprenta, fundaron Las hijas del Anáhuac (1873), semanario donde empezaron a integrar un tema significativo para el movimiento feminista: el derecho de las mujeres a recibir educación superior. Poco a poco, esos periódicos de finales del siglo XIX integraron otros puntos que se pueden relacionar con las propuestas feministas: el trabajo femenino, igualdad de salarios entre hombres y mujeres, discriminación a las primeras profesionistas, reflexiones sobre la identidad femenina e interés en romper con estereotipos de la época. A lo largo del siglo XX siguieron apareciendo estas publicaciones, como:

El álbum de la mujer (1883), de Concepción Gimeno. Violetas del Anáhuac (1887), de Laureana Wrigth. Siempreviva (1870), de Rita Zetina.

La mujer mexicana (1904), de Dolores Correa.

La mujer (1926), de María Ríos Cárdenas.

Ideas (1944), de Julia Nava.

Algunas ya declarando la identificación de su feminismo en la línea editorial de sus espacios, otras aprendiendo a negociar con su empresa periodística para insertar notas relacionadas con las mujeres y algunas abriendo en los diarios de circulación nacional desde columnas a suplementos para dar a conocer su perspectiva feminista.

Las periodistas más influyentes en esas épocas fueron: Adelina Zendejas, Elvira Vargas, Magdalena Mondragón, Rosario Castellanos, Sara Lovera y Esperanza Brito.

Pero, ¿cómo se ha desarrollado ese periodismo feminista? ¿Qué significa escribir periodismo feminista? A lo largo de este ensayo se detallarán estos puntos para identificarlo, comprenderlo y, de ser posible, practicarlo.

\section{Periodismo y feminismo en México}

El semanario La mujer mexicana (1904 y 1908) empezó a utilizar el término feminismo siempre con la intención de definirlo y de persuadir a las lectoras que al emplearlo no se referían a una guerra de sexos, sino al ideal de lograr la emancipación femenina en todos los ámbitos, desde el educativo hasta el cotidiano.

Poco después, otras dos periodistas lo aplicaron en sus publicaciones, Hermila Galindo fundó La mujer moderna (1915-1916) y María Ríos Cárdenas editó La mujer

\footnotetext{
* Este apartado es una síntesis del libro El género es el mensaje (2010), editado por la Universidad Autónoma del Estado de Hidalgo, cuya referencia completa se cita al final del ensayo.
} 
(1926-1929). Julia Nava de Ruisánchez fundó también, en la década de los veinte, una revista llamada Mujer, donde los temas y perspectivas se identificaban con el feminismo.

De manera marginal, siguieron apareciendo publicaciones cuya línea editorial era feminista, entre ellas Rueca (1941-1952). De 1963 a 1974 Rosario Castellanos aprovechó la página editorial de Excélsior para abordar temas sobre la situación de las mujeres (Hernández Carballido, Elvira, 2010).

En 1975 se llevó a cabo en nuestro país la Conferencia Mundial de las Naciones Unidas que lo declaraba como el Año Internacional de la Mujer. El gobierno de Luis Echeverría se vio obligado a modificar la Constitución Mexicana para promover la igualdad entre hombres y mujeres. Este espacio internacional dio un gran impulso al feminismo nacional y surgieron grupos que empezaron a debatir públicamente temas como el aborto, la violencia hacia las mujeres y la violación.

A esta ola que crecía en México y que cubrió lo que restaba del siglo XX, de 1976 a 1999, el periodismo también formó parte de ella. Fue así como aparecieron publicaciones como La Revuelta (1976-1978), Cihuat (1977-1978), La Boletina (1982-1986), La Correa Feminista (1991-1998), Fem (1976-2005) y DobleJornada (1987-1996).

En 1992 se fundó Comunicación e Información de la Mujer (CIMAC) que a partir de 1996 impartió por todos los estados del país un gran número de talleres para relacionar el periodismo y el feminismo.

En su mecánica, luego de integrar a cada grupo asistente, fue común la exposición de la directora de CIMAC, Sara Lovera, donde reconocía la importancia del periodismo, destacaba las cualidades del oficio, reconocía las dificultades de su práctica y reafirmaba el compromiso social de todo periodista que tiene un espacio en algún medio de comunicación. En seguida advertía de los temas "olvidados" por la rutina periodística y ponía gran énfasis y pasión para denunciar la invisibilidad femenina en los sucesos considerados como noticia. Con argumentos y ejemplos sólidos recordaba a las presentes el género al que pertenecían, un género al que olvidaban en búsqueda de la noticia del día cuando esa situación femenina latente en cualquier suceso pasa desapercibida por el sexismo, el sistema patriarcal y el machismo que caracteriza al periodismo. Invitaba de manera alentadora a hacer visibles a las mujeres e integrarlas a la información del medio en que se trabajaba (Hernádez-Carballido y Hernández, 2003) (Hernández, 2003).

Después de esa introducción se invitaba al grupo de periodistas a realizar una nota informativa de lo acontecido. Los textos periodísticos eran revisados por las responsables del taller y se indicaban los errores cometidos, principalmente se destacaba el olvido o poco énfasis en la presencia femenina y su relación con el tema expuesto. Se repartía material para que se descubriera la manera en que una nota podía redactarse con una perspectiva feminista, se ofrecían los documentos necesarios para profundizar en la información y transformar a las mujeres en sujetos de noticia. Entonces se pedía hacer otra nota con el mismo asunto visto en la conferencia y a manera de debate el grupo distinguía las diferencias y valoraba el logro de que las mujeres ya no fueran olvidadas en sus notas. Se incitaba a discutir lo que podían hacer en sus medios con esa nueva perspectiva.

En todos los talleres se dio a conocer el objetivo que les daba origen y razón de ser. Si bien fueron redactados de diversas maneras se distinguieron tres acciones básicas en todos ellos:

SENSIBILIZAR. Tanto en la redacción explícita de los objetivos, como en los discursos y tareas realizadas, puede distinguirse ese afán por involucrar a las periodistas en la situación de las mujeres, mirarlas, darles voz y buscar espacios para informar sobre ellas.

INFORMAR. Como una estrategia para atraer a las periodistas a los talleres, se ofreció informar sobre temas como la salud sexual y reproductiva, la democracia, la ciudadanía y los derechos humanos o asuntos que interesaran a la comunidad visitada. Aspecto que se cumplió al invitar especialistas en el tema a exponer sus conocimientos y al repartir materiales sobre el asunto abordado.

INVESTIGAR. Continuamente se invitó a las periodistas asistentes a los talleres a considerar la investigación como una herramienta básica para profundizar e informar de una manera más detallada y profesional.

En esa misma tendencia, la revista chilena Fempress editó uno de los primeros manuales para feministas que deseaban ejercer el periodismo. Además de dar definiciones y un contexto preciso, la obra aplicaba ejercicios para transformar el periodismo tradicional en feminista:

Instrucciones:

Evalúa durante dos o tres días los ejemplares de un periódico de circulación general y contesta las preguntas que se incluyen a continuación. Obtendrás así parámetros para considerar el medio como sexista o no sexista.

1) En las páginas principales del diario ( 5 o 10 , dependiendo del tamaño del periódico) compara las entrevistas hechas a hombres, y las que se hacen a mujeres de alto rango en el gobierno o la empresa privada, como parte de las noticias principales del día. Contabilízalos. Por ejemplo, $x$ noticias incluyen entrevistas con funcionarios, $x$ con funcionarias. 
2) Las noticias relacionadas con mujeres de alta jerarquía en gobierno o industria privada van acompañadas de fotos de las entrevistadas. Compáralas con las noticias relacionadas con hombres que se acompañan con fotografías.

3) En la sección de negocios compara las entrevistas con consultoras en finanzas, gerencia, economía, etcétera y las que se hacen a consultores, gerentes, economistas. 4) Los artículos que incluyen entrevistas con ejecutivas o funcionarias tienen descripción física de las entrevistadas, como, por ejemplo, la elegante ejecutiva, la funcionaria vestía un conjunto de punto crema, alta y delgada, de aspecto materna. A los ejecutivos, ¿se les describe de la misma manera?

5) Cuándo se entrevista a una mujer se le identifica como "la señora de Pérez o la señorita Pérez"', en vez de Pérez o su título profesional.

6) En la sección de cultura se incluyen comentarios críticos de obras escritas por mujeres y se incluyen artículos de expertas en este renglón. Compáralos con los que hacen a obras escritas por hombres.

7) En la sección de opinión/editorial se publican columnas sobre todos los temas. ¿Cuántas son escritas por hombres y cuántas por mujeres? (Amado, Hiriart, \& Valle, 1996)

Un ejemplo más reciente ocurrió en 2017, la oficina de Unesco México reunió a expertas en el tema para que de manera conjunta se redactara el contenido de un manual para estudiantes de comunicación y periodismo sobre indicadores de género en los medios de comunicación.

Las actividades y compromisos para desarrollar un periodismo feminista siguen en marcha. A continuación presentamos una propuesta para crear productos periodísticos con esa perspectiva, basada en nuestra experiencia y análisis a publicaciones feministas.

\section{La experiencia en los estados}

El periodismo feminista también ha estado presente en otras partes del país. Un ejemplo muy representativo es el suplemento Las Caracolas, fundado por Soledad Jarquín.

Por su parte, Aída Suárez, en el estado de Hidalgo, ha logrado abrir espacios tanto en prensa como en radio para abordar temáticas que expliquen la situación de las mujeres. En esta misma región, columnistas como Martha Canseco, Tania Meza, Elvira Hernández Carballido, Silvia Mendoza y Josefina Hernández Téllez han manifestado su feminismo en los temas elegidos para exponer cada semana en sus espacios periodísticos.

Cecilia Lavalle, desde Quintana Roo, a través de su columna Cristal de Roca cuestiona y denuncia la problemática de la población femenina al sur del país. En ese mismo estado, Lydia Cacho ha destacado por sus reportajes de constante denuncia.

En el norte, Leticia Castillo Quiñonez de la Universidad Autónoma de Ciudad Juárez, comparte su artículo Ellas contando su historia. Las periodistas en Ciudad Juárez, en donde hace un recuento del protagonismo de las mujeres en el periodismo en aquella ciudad fronteriza.

En el noroeste, Ana Imelda Coronel Cabanillas y Jorge Antonio Gastélum Escalante de la Universidad de Occidente, se dieron a la tarea de realizar la investigación sobre la Situación laboral de las periodistas en Culiacán, Sinaloa, desde una perspectiva de género. En ella, hacen énfasis en el notable incremento de la participación de la mujer en el periodismo. Sin embargo, agregan, esta feminización en la labor periodística no ha venido acompañada de una igualdad de oportunidades para hombres y mujeres y advierten que las mujeres siguen encontrando obstáculos para ascender en los medios de comunicación, para equiparar sus condiciones laborales con las de los hombres y para atender el trabajo con la familia.

En Jalisco, una joven reportera, Priscila Hernández, declaró abiertamente su compromiso con el periodismo feminista y dijo que formaba parte de la red de Comunicación e Información de la Mujer (CIMAC), donde publicaba reportajes y textos con este enfoque.

Yo lamento que este tema en Guadalajara no sea comprendido, dé miedo -ya sabes, lo clásico, ay yo no soy feminista-. En nuestra capital faltan muchas herramientas para empoderar a las mujeres periodistas, ellas siguen mucho la inercia conservadora que late en nuestra sociedad. Es difícil que encuentres un texto con enfoque feminista, es casi imposible que se quieran cubrir los eventos del movimiento de mujeres. Casi imposible que deseen las periodistas tomar un curso en $C I M A C$, el género no sirve para nada, qué horror ser feminista. Me sorprende e indigna cuando ellas aceptan condiciones que afectan sus posibilidades de vivir en una sociedad equitativa. Ya sabes, esa historia de diarios como "El Informador" que para entrar te pide examen médico para checar que no estás embarazada. A un compañero hombre nunca le preguntan cuántos hijos tiene, pero a una candidata a ser reportera, la interrogan sobre el número de hijos, que cómo se va a organizar para cumplir su rol de madre. Lo de no usar pantalón, la falda guardada en la bolsa y antes de llegar al periódico plancharla con las manos y a ponértela. ¿Se puede cambiar? ¿Reconocer esa situación? Por supuesto. Ahí está mi amiga Eli Rivera. Ella al principio negaba todo eso. La invité a cursos de CIMAC. Una vez, ante Sara Lovera dijo, yo no soy feminista. Sara le dijo, por qué. Argumentó. Lovera le dijo que eso no era feminismo, que cómo lo definía. Tampoco es eso. Lo niegas porque no lo comprendes, le advirtió. Luego de explicarlo con 
sencillez, mi amiga no ha vuelto a decir que no es feminista. El feminismo en Jalisco ha salido adelante $y$ ha propuesto cosas como la alerta de género, la tipificación del feminicidio. Enfrentan con bastante convicción ese sesgo machista y misógino que late en nuestra sociedad. Pero a veces lo hacen muy solas, las periodistas en general no han sabido apoyarlas y es una lástima. (Hernández Carballido E. , 2018)

\section{Pautas para el periodismo feminista}

Diversas autoras, manuales y periodistas que han abordado la tarea de hacer periodismo feminista coinciden en iniciar su propuesta precisando categorías, entre estas, dos que consideramos representativas. En el caso concreto de uno de los primeros manuales que apareció en México, El ABC del periodismo no sexista (1996), las autoras consideraron básico partir de estas dos categorías como punto de patida para distinguir a la prensa sexista. Este punto de partida resulta representativo para Ana María Amado, Bertha Hiriart y Norma Valle, para comprender el sistema donde se pretende desarrollar el periodismo feminista, para identificar los prejuicios sexistas que hacen más complejos sus objetivos: y para reconocer que el contexto y sus expresiones son construcciones culturales que tienen un origen -el patriarcado- y una representación -el sexismo-. Por ello, identificar estas dos palabras y definirlas lo consideran una tarea prioritaria:

\section{- $\quad$ SISTEMA PATRIARCAL. Manifestación e institucionalización del dominio masculino sobre las mujeres. \\ - SEXISMO. Ideología de la supremacía masculina que denigra todo lo relacionado con lo femenino. Lo excluye, lo hace invisible o lo minimiza.}

Si bien presentan un panorama que explique esta situación, no se quedan en la crítica o en los señalamientos, siempre coinciden en compartir que ese escenario es posible de transformar sensibilizando a través de diplomados, cursos, talleres y materias integradas a un plan de estudios de las licenciaturas de comunicación y periodismo. Para ello, proponen cumplir con los siguientes objetivos:

- Reflexionar sobre la labor periodística y discutir cómo visibilizar la condición social de las mujeres en los medios de comunicación.

\footnotetext{
* Esta propuesta retoma las ideas y estrategias publicadas en los libros: $E l A, B, C$ del periodismo no sexista, El sexo en la noticia y Hacia la construcción de un periodismo no sexista, cuya ficha completa está en las referencias finales.
}

- Crear conciencia entre los y las comunicadoras que laboran diariamente en los medios de comunicación sobre la importancia de las acciones de las mujeres en los espacios públicos.

- Sensibilizar a las comunicadoras que laboran diariamente en los medios de comunicación sobre la importancia de hacer visibles a las mujeres como ciudadanas y sujetos sociales.

- Movilizar sus inquietudes para continuar en la investigación, elaboración y difusión de la problemática femenina.

- Evidenciar en los medios de comunicación la situación de las mujeres y promover el cambio de su condición actual en la sociedad.

- Incluir la presencia de las mujeres en los medios y tratamiento de información no discriminatoria. (Velázquez, 2009).

Cuando cada periodista comprende y respeta esta manera de sensibilizar, podrá intentar o empezará a redactar sin prejuicios sexistas su información. En los manuales citados, se especifica lo que significa ser no sexista.

Denunciar la opresión, la cual es descrita por Marcela Lagarde como la manera en que el sistema somete y discrimina a las mujeres, en los diferentes espacios profesionales. A juicio de la autora, una forma representativa de entender la opresión de las mujeres es el término que ella denominó cautiverios, una categoría antropológica que sintetiza el hecho cultual que define el estado de las mujeres en el mundo patriarcal: se concreta políticamente en la relación específica de las mujeres con el poder y se caracteriza por la privación de la libertad, por lo tanto estás oprimidas y limitadas a comportarse como madresposas y/o locas, monjas, putas o presas.

- Poner en evidencia y denunciar aquello que les es adjudicado a las mujeres desde el estereotipo o la convención.

- Tener una perspectiva crítica de la virilidad reducida a la fuerza física o al gusto por el poder y dominar a quien se considera.

- Mostrar la participación masculina en cada espacio cotidiano y advertir la presencia femenina en los ámbitos públicos. Pero ambos espacios deben ser compartidos y posibles de habitar por igual por hombres y mujeres.

- Dignificar las imágenes que ponen en escena de manera destacada a las mujeres como tal.

- Buscar la mutilación de roles femeninos y masculinos. 
La estrategia para lograr hacer periodismo feminista, puede ser desarrollada en diversas etapas (Bach, 2000), que desde nuestra perspectiva pueden ser tres muy concretas:

1. EL CONTEXTO. Quien se proponga realizar periodismo feminista debe identificar el escenario que está cubriendo, y reconocer que en ese escenario están las mujeres y los hombres. Tanto a ellas como a ellos debe darles un papel protagónico en su texto, sin subordinar los asuntos protagonizados por hombres 0 viceversa. Dar voz a las mujeres y hombres, así como recordar la pluralidad existente en su público.

2. LA FORMA DE REDACTAR. Si bien, hasta la fecha, se discute el uso del llamado lenguaje incluyente, consideramos que una alternativa más viable es evitar el genérico masculino para dominar a colectivos mixtos, con la finalidad de hacer más visibles a las mujeres. De igual manera, al momento de describir no asignar estereotipos ni ubicar a cada persona por su parentesco, en el caso de las mujeres no dar la referencia que es hija, esposa o madre de alguien, sino identificarla por sus propios méritos o características. Desaparecer los marcadores de sexo como señora, señorita, doña, entre otros.

3. EL COMPROMISO. El periodismo feminista nunca se impone, debe surgir por voluntad propia, por convicción luego de comprender que las mujeres deben ser visibilizadas de manera equitativa en los medios de comunicación.

\section{La práctica y lo posible}

Otra propuesta fue presentada en el capítulo Las voces feministas que afinan género, periodismo y comunicación en México*, donde se afirmó que una periodista con un compromiso feminista podría cubrir un suceso noticioso con una mirada transversal a la sociedad. La diferencia y características entre el periodismo sexista y feminista son:

\begin{tabular}{|l|l|}
\hline Periodismo sexista & \multicolumn{2}{l|}{ Periodismo feminista } \\
\hline Toma en luenta & Se reconoce a las mujeres por \\
fundamentalmente el parentesco & sus logros personales y \\
o la relación que las mujeres & acciones en los escenarios \\
tienen con un hombre, es decir & profesionales, sociales, \\
si son esposas, acompañantes o & culturales y hasta personales. \\
hijas de un prominente político o & No se les adjetiva, sino que se \\
un destacado personaje social. & identifica y se reconocen sus \\
No importa identificarlas sino & aportaciones a la vida social. \\
\hline
\end{tabular}

* Publicado en: Voces diferentes: Mujeres científicas en México, coordinadora: Rosa María Valles, UAEH, 2012.

\begin{tabular}{|c|c|}
\hline $\begin{array}{l}\text { adjetivarlas ya sea por las } \\
\text { circunstancias en que aparecen } \\
\text { o por sus características físicas. }\end{array}$ & $\begin{array}{l}\text { Un ejemplo es la página } \\
\text { mujeresnet, fundada por Elsa } \\
\text { Lever, donde cada columna y } \\
\text { cada texto publicado, reconoce } \\
\text { la presencia femenina en todos } \\
\text { los escenarios sociales. }\end{array}$ \\
\hline $\begin{array}{l}\text { En la sección de política los que } \\
\text { producen información y hacen } \\
\text { cualquier tipo de declaraciones } \\
\text { son en su mayoría hombres, y } \\
\text { las contadas ocasiones que se } \\
\text { cita a las mujeres es porque el } \\
\text { caso se trata como algo insólito, } \\
\text { digno de burla, crítica o } \\
\text { anecdótico. }\end{array}$ & $\begin{array}{l}\text { Se reconocen las opiniones de } \\
\text { hombres y mujeres en el } \\
\text { escenario político, sin } \\
\text { distinciones por su género. En } \\
\text { el periódico "Libre por } \\
\text { convicción. El Independiente } \\
\text { de Hidalgo", las columnas de } \\
\text { Josefina Hernández Téllez son } \\
\text { un ejemplo claro de esta } \\
\text { característica, ya que ella } \\
\text { puede hacer referencia, por } \\
\text { ejemplo, a un defensor o } \\
\text { defensora de audiencias y } \\
\text { puntualizar sus acciones de } \\
\text { acuerdo a sus compromisos y } \\
\text { nunca tomando en cuenta si se } \\
\text { trata de un hombre o mujer. }\end{array}$ \\
\hline $\begin{array}{l}\text { En la sección de sociedad o nota } \\
\text { roja las mujeres aparecen ya } \\
\text { sea porque fueron golpeadas, } \\
\text { asesinadas, violadas } \\
\text { engañadas. La población } \\
\text { femenina parece convertirse en } \\
\text { noticia únicamente si es objeto } \\
\text { de agresiones, por su debilidad } \\
\text { natural se les reporta como } \\
\text { víctimas y resignadas a su triste } \\
\text { destino de sufrimiento constante. } \\
\text { El discurso expositivo sobre la } \\
\text { violencia específica contra las } \\
\text { mujeres es un tema habitual } \\
\text { pero nunca con un tono de } \\
\text { denuncia sino con frialdad o } \\
\text { truculencia, magnificando el } \\
\text { hecho con el abuso de adjetivos } \\
\text { para aumentar el posible } \\
\text { impacto dirigido a despertar la } \\
\text { morbosidad de los lectores. }\end{array}$ & $\begin{array}{l}\text { El tono de denuncia } \\
\text { caracteriza los casos de } \\
\text { violencia en contra de las } \\
\text { mujeres. El trabajo realizado } \\
\text { Layla Sánchez Kuri en su } \\
\text { página de facebook "La ciudad } \\
\text { de las mujeres" da a conocer la } \\
\text { situación de violencia que } \\
\text { viven las mujeres. Sus textos } \\
\text { son respetuosos al hacer } \\
\text { referencia a la víctima y pese a } \\
\text { lo trágico de las situaciones, } \\
\text { jamás presenta un tono que no } \\
\text { sea el de denuncia. }\end{array}$ \\
\hline $\begin{array}{l}\text { Los espacios destinados a los } \\
\text { espectáculos o cultura se } \\
\text { aprovechan para presentar } \\
\text { perfiles femeninos desde una } \\
\text { perspectiva de diversión y ocio, }\end{array}$ & $\begin{array}{l}\text { En las secciones de } \\
\text { espectáculos, deportes y } \\
\text { cultura se rompe con } \\
\text { estereotipos y cautiverios para } \\
\text { presentar a las mujeres por }\end{array}$ \\
\hline
\end{tabular}




\begin{tabular}{|c|c|}
\hline $\begin{array}{l}\text { la labor creativa de las actrices } \\
\text { se minimiza al centrar el } \\
\text { discurso en su belleza física. De } \\
\text { posibles protagonistas terminan } \\
\text { como un adorno digno de } \\
\text { admirar, relacionándolas con la } \\
\text { cursilería y el lucimiento de su } \\
\text { cuerpo por encima de cualquier } \\
\text { actitud intelectual. }\end{array}$ & $\begin{array}{l}\text { sus logros, retos y dificultades. } \\
\text { Un ejemplo es el trabajo de } \\
\text { Elina Hernández en la revista } \\
\text { FEM en su columna De atletas; } \\
\text { otro caso es el de la periodista } \\
\text { Claudia Pedraza quien en sus } \\
\text { investigaciones, destaca a las } \\
\text { mujeres futbolistas por su } \\
\text { habilidad dentro de la cancha. } \\
\text { Poco a poco van llegando } \\
\text { reporteras a estos espacios. } \\
\text { En Hidalgo las reporteras } \\
\text { Emma Fermín, Fernanda } \\
\text { Aguilar e Iraís Flores han } \\
\text { abordado los temas deportivos } \\
\text { con calidad y experiencia, } \\
\text { dándoles un tratamiento } \\
\text { protagónico a las mujeres en } \\
\text { las notas deportivas. }\end{array}$ \\
\hline
\end{tabular}

Hernández Carballido, Las voces feministas que afinan género,periodismo y comunicación en México, 2009

La revista del Instituto Estatal Electoral de Hidalgo, en 2015, presentó un número especial sobre la participación de las mujeres en la política del estado. La coordinadora del número fue Elsa Ángeles, quien cuidó que los textos cumplieran con el enfoque feminista:

- Cuestionar las relaciones desiguales de poder entre hombres y mujeres.

- Persuadir para la transformación de esas relaciones.

- Cambiar la imagen estereotipada tanto femenina como masculina.

- Entregar una visión más equilibrada de su diversidad y contribuciones a la sociedad.

Un ejemplo de ese trabajo es una de las entrevistas realizadas para dicha publicación, donde se intentó cumplir con esos objetivos. Ha sido utilizada como ejemplo de periodismo feminista y se le realizó a Balbina Mariana Cruz. A continuación, su contenido y el objetivo que cumple:

\begin{tabular}{|l|l|}
\hline Texto periodístico & \multicolumn{1}{|c|}{$\begin{array}{l}\text { Objetivos del } \\
\text { periodismo feminista }\end{array}$} \\
\hline "Yo fui una persona muy pobre, mi & Cambiar la imagen \\
familia dormía en el piso, no teníamos ni & estereotipada tanto \\
para comer, pero algo dentro de mí & femenina como \\
logró darme la fuerza para salir & masculina. \\
adelante. Sin tener ninguna meta, sin & \\
más ambición que salir adelante, pude & \\
estudiar, hacer una licenciatura, apoyar & \\
\hline
\end{tabular}

a mis hijas, tomar decisiones, hacerme escuchar y respetar..." $Y$ esa fuerza salió de su alma.

Sentadas en el pretil de una ventana, la voz de Balbina Mariana Cruz Cardón hace vibrar desde los cristales hasta las bisagras. Su historia abre de par en par la certeza de que existen mujeres sencillamente sabias, que de la necesidad van bordando momentos, corajes e inspiraciones para darle fuerza a su alma.

Nacida en Cardonal, Hidalgo, lágrimas otomíes la hicieron navegar en una infancia difícil pero seguramente la montañosa y accidentada geografía del lugar donde nació, marcó un destino que de la necesidad pasó al orgullo de su propia vida.

El significado de su propia localidad delata la fuerza de su alma, esa tierra que por su color anunciaba tiempos difíciles, poco a poco logró parir cardones, espigados, quizá con espinas, pero siempre creciendo con la certeza de llegar a los cielos, a las nubes, a la parte más alta que puede asemejarse al reconocimiento, el mismo que desde hace mucho tiempo doña Balbina ha recibido de parte de su comunidad, de su espacio laboral, de su familia y de las mujeres que la conocen.

\section{La necesidad}

"Mi familia fue muy pobre. Muchas veces no teníamos para comer. Mi papá ganaba muy poco, a veces se lo gastaba en pulque. Tal vez para olvidar su tristeza de vernos tan desamparados, con tantas carencias. Pero yo pude ir a la escuela y por eso digo que ha sido la necesidad lo que me dio fuerza. Yo estudiaba, pero quería irme a México a trabajar, para ayudar en mi casa. Soy la segunda, primero mi hermano y luego yo, mi hermana y mi otro hermano. Yo quería ayudarlos."

Fue así como Balbina logró conseguir trabajo mientras cursaba el tercer año. Su maestra la invitó a que en
Entregar una visión más equilibrada de su diversidad $\quad \mathrm{y}$ contribuciones a la sociedad. 
vacaciones le ayudara a cuidar a sus hijas, a arreglar su casa. De esa manera, cada periodo vacacional se iba a trabajar a las casas de varias maestras.

"Yo no pensaba en estudiar más, quería tener dinero para que mi familia comiera. Así me fui a México, trabajé en varias casas. Una vez me fui con una tía que era la muchacha de una señora que tenía chofer y muchas cosas. $Y$ esa señora le preguntó a mi tía: ¿Y esta niña, no va a la escuela? Pues no, yo quería trabajar. Pero gracias a esa señora estudié por las noches para terminar la secundaria. Entonces trabajaba y estudiaba. Poco a poco perdí mi timidez, mi abnegación y ese silencio que me envolvía para preguntar, para estar atenta, para aprender mucho. Así supe que había un lugar donde solicitaban promotores indígenas para enseñar en comunidades a las poblaciones infantiles. Entonces, me hice promotora."

\section{La trayectoria}

Balbina evoca con verdadero gozo esos días de estudio, el orgullo de ser promotora de educación preescolar indígena. Los primeros trabajos fuera del estado de Hidalgo, irse a otras comunidades donde para llegar caminaba horas y horas, y a cada paso la certeza de seguir estudiando, la necedad de especializarse, de fortalecer su conocimiento y no dejar de aprender. "Luego que me entero que había otra especialidad en el mejoramiento profesional para promotores bilingües, y durante tres años la cursé y me dieron mi certificado. No fue fácil, porque mientras hacía mis tareas, yo seguía yendo a las comunidades a apoyarlos con mis trabajos para preescolar, seguía caminado y caminando para llegar y compartir lo que había aprendido. Por estudiar en ese nivel, ahora considerado como la Normal Básica, pude después inscribirme en la Universidad

Cuestionar las
relaciones desiguales de poder entre hombres y mujeres.

Persuadir para la transformación de esas relaciones.
Pedagógica Nacional y tener una beca eso fue en 1997."

Sin dejar de trabajar ni de estudiar, ella empezó a identificar las necesidades de educación de las comunidades indígenas, participó en proyectos para independizar al preescolar de la primaria, dar cursos, hacer materiales didácticos y hasta reconocer la existencia de un día de la educadora que ellas merecían también celebrar.

"Busqué mi cambio, quería ir a mi comunidad y poco a poco me fui acercando. Primero logré que me asignaran en Nicolás Flores y luego al Cardonal, ya con mi título."

Pero además de ser la maestra, la confianza y seguridad la animó a participar en otras actividades para ayudar a su comunidad. "Entonces fui presidenta de la Comisión de Recursos Económicos de la comunidad, pues luego piden dinero para muchas cosas y no se ve ningún cambio. Estuve muy atenta de los montos que se tenían y en qué se gastaba. También he sido perito del comité que supervisó y vigiló que las obras y apoyos del programa dedicado a sensibilizar para erradicar la violencia contra las mujeres se desarrollaran con transparencia y calidad. Fui jefa del sector de educación preescolar indígena. $\mathrm{Y}$ aunque falta poco para la jubilación no he pensado en hacerlo, mientras tenga salud andaré en estas cosas."

\section{La maternidad}

"En la comunidad me rechazaron mucho, no me querían ni ver, me tachaban de mala porque he tenido dos hijas sin ningún apoyo ni presencia del padre. Nunca lo he necesitado y preferí ser padre y madre a la vez. Fue difícil, nadie me ofreció ningún apoyo, pero no me arrepiento porque yo no espero ningún tipo de reconocimiento, aunque la comunidad poco a poco ha tenido que incorporarme a sus espacios y actividades porque con mi trabajo les he

\section{Cuestionar las} relaciones desiguales de poder entre hombres y mujeres.

Persuadir para la transformación de esas relaciones.

Cambiar la imagen estereotipada tanto femenina como masculina. 


\begin{abstract}
demostrado mi valor".
Hablar de sus hijas de inmediato ilumina su mirada y sus manos de mujer trabajadora parecen acariciar los rostros de esas dos mujeres que ella parió.

"Yo siempre les he dicho a mis hijas, no dependan de nadie, solamente dependan del estudio. Primero estudien y luego hagan lo que quieran, si se quieren casar que lo hagan, si no se quieren casar, no lo hagan; si quieren tener hijos pues que los tengan, pero ya que han hecho su carrera y puedan darles lo necesario. No esperen a ningún hombre. Ustedes como yo, pueden abrirse camino solas."

Por supuesto que las convenció. Su hija mayor, quien ya tiene 30 años, primero estudió derecho, pero vio que no era su vocación y ahora se fue a Querétaro para estudiar en la Universidad Pedagógica. Ya le dio una nieta. La segunda hija estudió turismo y ha logrado integrarse a compañías con las que conoce el mundo.
\end{abstract}

\section{Las mujeres}

Pero lo que ha logrado con sus hijas no siempre sucede con sus compañeras, amigas, vecinas, aliadas...

"Con tristeza veo que pocas mujeres se integran a estos espacios sociales. Tienen miedo, no se atreven a tener voz ni voto, dependen mucho de sus maridos, creen que ellas no pueden decidir, exigir, cuestionar. Pero yo les digo que deben atreverse, aunque muy pocas me hacen caso. Que tengan valor, que tienen valor, que tenemos derechos. Que no les crean a los hombres cuando dicen que pueden más que nosotras. Yo estoy segura de que somos más inteligentes.

"Yo les digo a mis hijas, nosotras tres salimos adelante solitas, pero si llega a nuestro lado un hombre, que sea para ser nuestro compañero, no nuestro enemigo. Dígame, ¿qué gana una mujer de sentir que duerme junto a alguien si esa persona la trata como su peor
Cuestionar las "Si me ofrecieran un puesto de decisión, relaciones desiguales seguro le entraría si se trata de ayudar a de poder entre mi comunidad, -que ahora me respeta hombres y mujeres. $\quad$ mucho porque sabe que cuentan conmigo-; si con eso lograra despertar a las mujeres que conozco -que dejen de ser dependientes-, yo sí haría cosas por el pueblo. Eso sí, lo haría sin dejar mi trabajo en el preescolar."

"No tengo planes, aunque sí muy claro que no quiero ser una mujer común, y mientras pueda seguiré transmitiendo energía positiva."

Balbina Mariana Cruz Cardón, maestra de preescolar por vocación, orgullosa de su origen, madre/padre de sus hijas, voz que se hace respetar en las reuniones de su comunidad, segura de las posibilidades de crecimiento de toda mujer, se despide de mí para seguir detrás de sus convicciones, guiada por la fuerza de su alma.

Fuente: Hernández Carballido, De la necesidad a la fuerza del alma, 2015.

Cuestionar las
relaciones desiguales de poder entre hombres y mujeres.

Persuadir para la transformación de esas relaciones.

Cambiar la imagen estereotipada tanto femenina como masculina.

Entregar una visión más equilibrada de su diversidad $y$ contribuciones a la sociedad. 


\section{Conclusiones}

El recorrido realizado por este tema permite precisar el significado del periodismo feminista y especificar sus características de forma y contenido, que a nuestro juicio son:

- Denunciar la opresión, entendida como la manera en que el sistema somete y discrimina a las mujeres, en los diferentes espacios profesionales.

- Poner en evidencia y denunciar aquello que les es adjudicado a las mujeres desde el estereotipo o la convención.

- Tener una perspectiva crítica de la masculinidad hegemónica.

- Mostrar la participación masculina en cada espacio cotidiano y advertir la presencia femenina en los ámbitos públicos. Pero ambos espacios deben ser compartidos y posibles de habitar por igual por hombres y mujeres.

- Dignificar las imágenes que ponen en escena de manera destacada a las mujeres como tal.

NOTAS

[1] De acuerdo con Celia Amorós (2001), por feminismo de la igualdad puede entenderse aquel que plantea la igualdad de derechos para las mujeres en todos los ámbitos, tanto de la vida pública como de la privada: las prácticas apuntan, por lo tanto, a reivindicar la equidad de hombres y mujeres en los planos jurídicos, legales, políticos, económicos, etc.

[2] Este apartado es una síntesis del libro El género es el mensaje (2010), editado por la Universidad Autónoma del Estado de Hidalgo, cuya referencia completa se cita al final del ensayo.

[3] Esta propuesta retoma las ideas y estrategias publicadas en los libros: El A, B, C del periodismo no sexista, El sexo en la noticia y Hacia la construcción de un periodismo no sexista, cuya ficha completa está en las referencias finales.

[4] Publicado en: Voces diferentes: Mujeres científicas en México, coordinadora: Rosa María Valles, UAEH, 2012. Referencias Bibliográficas

\section{Referencias bibliográficas}

Amado, A. M., Hiriart, B., \& Valle, N. (1996). El abc de un periodismo no sexista. Santiago de Chile: Fempress.

Amoros, C. (2001). Feminismo: igualdad y diferencia. México: Universidad Nacional Autónoma de México.

Bach, M. (2000). El sexo de la noticia. Barcelona: Icaria.

Beauvoir, S. (2016). El segundo sexo. México: Penguin Randon House.

Castellanos, R. (1976). La liberación de la mujer aquí. En El uso de la palabra. México: Editores Mexicanos Unidos.

DobleJornada. (8 de marzo de 1987). Editorial. La Jornada, pág. 1.
Hernández Carballido, E. (2009). "Las voces feministas que afinan género, periodismo y comunicación en México". En R. Valles, Voces diferentes (pp. 43-70). Hidalgo: Universidad Autónoma del Estado de Hidalgo.

Hernández Carballido, E. (2010). El género es el mensaje. Hidalgo: Universidad Autónoma del Estado de Hidalgo.

Hernández Carballido, E. (2015). "De la necesidad a la fuerza del alma". Letras para la democracia, 34-36.

Hernández Carballido, E. (2018) Las informadoras. Mujeres periodistas en Guadalajara. Hidalgo: Universidad Autónoma del Estado de Hidalgo.

Hernández Téllez, J. (1988). “Sara Lovera”. Fem, 35.

Hernández, E. y Hernández. J. (2003). Formando periodistas: La experiencia de CIMAC. México: CIMAC.

Lovera, S. (2019). "Periodismo feminista en México", conferencia impartida en la Escuela Feminista, Ciudad de México, Centro Cultural España.

Sefchovich, S. (2011). ¿Son mejores las mujeres? México: Paidós.

Velázquez, C. (2009). Hacia la construcción de un periodismo no sexista. México: Cimac. 